\title{
Erratum: Billion dollar babies_-biotech drugs as blockbusters
}

Stacy Lawrence

Nature Biotechnology 25, 380-382 (2007); published online 03 April 2007; corrected after print 1 June 2007.

In the version of this article initially published, the subheadings for Table 1 , columns three and four should have said (\$ billions) rather than (\$ millions).

\footnotetext{
흘 Corrigendum: Toll-free vaccines?

Arthur M Krieg

Nature Biotechnology 25, 303-305 (2007); published online 7 March 2007; corrected after print 1 June 2007.

In the version of this article initially published, reference 1 is incorrect. The correct reference is Gavin, A.L. et al. Science 314, 1936-1938 (2006).

The incorrect reference has been replaced in the HTML and PDF versions of the article.

\section{Addendum: Response to "Blame factory farming, not organic food"}

\section{Nature Biotechnology responds}

Nature Biotechnology 25, 165-166 (2007); published online 7 February 2007; corrected after print 1 June 2007.

The following information was not available when this correspondence response was initially published. At a California Senate hearing held on Tuesday, February 28, 2007, California Department of Health Services officials, under direct questioning by Senator Maldonado, indicated that the outbreak of E. coli O157:H7 in spinach originated from an organic farm, contrary to the statements made by Craig Holdrege. The entire hearing can be found at http://www.calchannel.com/archive.php by looking under February 2007, 022807, "Food-Borne Illness"; the comments relating to the organic source of the outbreak occur $~ 10$ minutes into the hearing (after formalities). This addendum has been added to the HTML and PDF versions of the article.
} 